Delft University of Technology

\title{
Grand Research Challenges for Sustainable Industrial Biotechnology
}

Straathof, Adrie J.J.; Wahl, S. Aljoscha; Benjamin, Kirsten R.; Takors, Ralf; Wierckx, Nick; Noorman, Henk J.

DOI

10.1016/j.tibtech.2019.04.002

Publication date

2019

Document Version

Accepted author manuscript

Published in

Trends in Biotechnology

\section{Citation (APA)}

Straathof, A. J. J., Wahl, S. A., Benjamin, K. R., Takors, R., Wierckx, N., \& Noorman, H. J. (2019). Grand Research Challenges for Sustainable Industrial Biotechnology. Trends in Biotechnology, 37(10), 1042-1050. https://doi.org/10.1016/j.tibtech.2019.04.002

\section{Important note}

To cite this publication, please use the final published version (if applicable).

Please check the document version above. 


\section{Delft University of Technology}

\section{Grand Research Challenges for Sustainable Industrial Biotechnology}

Straathof, Adrie J.J.; Wahl, Aljoscha; Benjamin, Kirsten R.; Takors, Ralf; Wierckx, Nick; Noorman, Henk DOI

10.1016/j.tibtech.2019.04.002

Publication date

2019

Document Version

Accepted author manuscript

Published in

Trends in Biotechnology

\section{Citation (APA)}

Straathof, A. J. J., Wahl, S. A., Benjamin, K. R., Takors, R., Wierckx, N., \& Noorman, H. J. (2019). Grand Research Challenges for Sustainable Industrial Biotechnology. Trends in Biotechnology.

https://doi.org/10.1016/j.tibtech.2019.04.002

\section{Important note}

To cite this publication, please use the final published version (if applicable).

Please check the document version above.

\section{Copyright}

Other than for strictly personal use, it is not permitted to download, forward or distribute the text or part of it, without the consent of the author(s) and/or copyright holder(s), unless the work is under an open content license such as Creative Commons.

\section{Takedown policy}

Please contact us and provide details if you believe this document breaches copyrights.

We will remove access to the work immediately and investigate your claim. 


\title{
Grand research challenges for sustainable industrial biotechnology
}

\author{
Adrie J. J. Straathof*1, S. Aljoscha Wahl1, Kirsten R. Benjamin'², Ralf Takors ${ }^{3}$, Nick Wierckx ${ }^{4}$, \\ Henk J. Noorman" ${ }^{1,5}$ \\ ${ }^{1}$ Delft University of Technology, Department of Biotechnology, van der Maasweg 9, 2629 HZ Delft, \\ The Netherlands. \\ ${ }^{2}$ Amyris, 5885 Hollis Street, Suite 100, Emeryville, CA 94608, USA. \\ ${ }^{3}$ Institute of Biochemical Engineering, University of Stuttgart, Allmandring 31, 70569 Stuttgart, \\ Germany. \\ ${ }^{4}$ Institute of Bio- and Geosciences, IBG-1: Biotechnology, Forschungszentrum Jülich GmbH, 52425 \\ Jülich, Germany. \\ ${ }^{5}$ DSM Biotechnology Center, PO Box 1, 2600 MA Delft, The Netherlands. \\ *Correspondence: a.j.j.straathof@tudelft.nl (A.J.J. Straathof).
}

Keywords: bio-based production; systems biotechnology; bioprocess engineering; biological engineering; industrial fermentation

\begin{abstract}
Future manufacturing will focus on new, improved products, and new, improved production methods. Recent biotechnological and scientific advances, such as CRISPR-Cas and various omics technologies, pave the way to exciting novel biotechnological research, development, and commercialization of new sustainable products. Rigorous mathematical descriptions of microbial cells and consortia thereof will enable deeper biological understanding and lead to powerful in silico cellular models. Biological engineering, i.e. model-based design together with synthetic biology, will accelerate the construction of robust and high-performing microorganisms. Using these organisms, and ambitions towards zero-concepts with respect to emissions and excess resources in bioprocess engineering, industrial biotechnology is expected to become highly integrated into sustainable generations of technology systems.
\end{abstract}

\section{Drivers for renewable industrial biotechnology}

Humankind desires new, improved products, and new, improved methods for manufacturing. For production of fuels, chemicals, and materials, replacing fossil feedstocks by renewable resources is crucial to meet United Nations sustainable development goals (www.un.org), such as reducing pollution and reaching agreed climate change targets. Expectations are that biotechnology will play a major role in this, considering that developments in renewable bio-based industrial production have a history of about 50 years with continuously increasing performance on economic, 
environmental and social targets, and still major progress to come. Microbial conversion of renewable resources is an inherently compelling and advantageous concept because cell factories are designed for high conversion selectivity and adaptability, and require only a modest infrastructure (Box 1).

Novel research and development in the industrial biotechnology field is enabled due to various scientific and engineering advances. Here we discuss the most promising technologies and approaches from our point of view.

Sustainable production of organic compounds requires a renewable carbon source, and in addition a renewable energy source if the carbon source does not contain sufficient energy. Several generations of biotechnical processes can be distinguished, as summarized in Table 1. The advantages and disadvantages of the early generations are generally known.

Table 1. Overview of processes for using renewable resources in industrial biotechnology.

\begin{tabular}{|c|c|c|c|c|}
\hline Generation & Status & Advantages & Disadvantages & Ref. \\
\hline $\begin{array}{l}\text { 1. Sugar/starch } \\
\text { fermentation (also } \\
\text { triglycerides/glycerol) }\end{array}$ & $\begin{array}{l}\text { About } 1000 \\
\text { biorefineries } \\
\text { worldwide produce } \\
1 \mathrm{G} \text { bioethanol }\end{array}$ & State-of-the-art & $\begin{array}{l}\text { Competition with } \\
\text { food/feed }\end{array}$ & \\
\hline $\begin{array}{l}\text { 2. Lignocellulosic } \\
\text { hydrolysate fermentation } \\
\text { (also other waste) }\end{array}$ & $\begin{array}{l}\text { Less than } 10 \\
\text { biorefineries } \\
\text { worldwide produce } \\
2 \mathrm{G} \text { bioethanol; } \\
\text { other products } \\
\text { might follow }\end{array}$ & $\begin{array}{l}\text { Valorization of non- } \\
\text { food, waste biomass }\end{array}$ & $\begin{array}{l}\text { Biomass } \\
\text { pretreatment } \\
\text { and hydrolysis, } \\
\text { lignin utilization }\end{array}$ & {$[67]$} \\
\hline 2a. Syngas fermentation & $\begin{array}{l}\text { First commercial } \\
\text { plant started for } \\
\text { ethanol from fossil } \\
\text { syngas; not yet } \\
\text { from bio-syngas, i.e. } \\
\text { gasified biomass }\end{array}$ & $\begin{array}{l}\text { Valorizing gases } \\
\text { from steel and } \\
\text { cement industry; } \\
\text { full use of } \\
\text { lignocellulosic } \\
\text { biomass, incl. lignin; } \\
\text { flexible feedstock } \\
\text { (ranging from } \mathrm{CO} \text { to } \\
\mathrm{H}_{2} \text { plus } \mathrm{CO}_{2} \text { ) }\end{array}$ & $\begin{array}{l}\text { Biomass } \\
\text { gasification; } \\
\text { Gas/liquid mass } \\
\text { transfer }\end{array}$ & $\begin{array}{l}{[21,} \\
68] \\
{[69]}\end{array}$ \\
\hline $\begin{array}{l}\text { 3. Using microalgae or } \\
\text { phototrophic bacteria }\end{array}$ & $\begin{array}{l}\text { Many pilots and } \\
\text { demos; commercial } \\
\text { for feed production }\end{array}$ & $\mathrm{CO}_{2}$ utilization & $\begin{array}{l}\text { 2D factories and } \\
\text { transport issues } \\
\text { upon scale-up }\end{array}$ & {$[70]$} \\
\hline $\begin{array}{l}\text { 3a. Macroalgae (off- } \\
\text { shore) }\end{array}$ & $\begin{array}{l}\text { Focus on food; } \\
\text { Research on other } \\
\text { application areas. }\end{array}$ & $\mathrm{CO}_{2}$ utilization & $\begin{array}{l}\text { Conversion } \\
\text { specificity; } \\
\text { Logistics }\end{array}$ & \\
\hline 4. E-driven fermentation & Conceptual designs & $\begin{array}{l}\text { Renewable } \\
\text { electricity and } \mathrm{CO}_{2} \\
\text { and/or waste }\end{array}$ & $\begin{array}{l}\text { Electricity-cell } \\
\text { interface }\end{array}$ & {$[1]$} \\
\hline
\end{tabular}

With the rapid and precise microbial strain construction methods and improved modelling of cell behavior in process systems, we can now start working on fourth generation processes (see 
Glossary). These focus on a combination of renewable carbon inputs with renewable electric power, in particular solar or wind, as electron source [1]. It is envisaged that such power will become the dominant form of energy, especially in urban areas, so geographically distributed biomass can be used more efficiently in a cascading approach providing food, feed and the necessary carbon source for chemicals, while less will be used for energy. Coupling of separate carbon and energy sources can be accomplished either directly or indirectly, as explained below.

The direct route is electro-fermentation [2], in which the microorganism employs an electrode as electron source or sink. This can change the thermodynamic feasibility of redox reactions, and in the future, especially when using engineered microorganisms, might allow anaerobic production of a wide range of chemicals. Carbon yield losses and operational costs associated with aerobic production [3] might be avoided. Even products containing elements not sufficiently present in biomass might become accessible via biotechnology, without using fossil sources (Box 2).

The carbon for electro-fermentation might be originating from biomass, or more commonly from $\mathrm{CO}_{2}$ (then called "microbial electrosynthesis"). A relatively high energy input is required for converting $\mathrm{CO}_{2}$ into useful products and for obtaining relevant dissolved $\mathrm{CO}_{2}$ concentrations, however. Development of suitable microorganisms and scalable equipment for electro-fermentation and microbial electrosynthesis are formidable challenges. Direct transfer of electrons to biofilms on electrodes is limited by surface-to-volume restrictions in large-scale applications. This may be ameliorated by using soluble redox mediators [4], or "cable bacteria" that are still poorly understood [5].

Indirect routes for electron uptake involve methods such as converting electric power electrochemically into $\mathrm{H}_{2}$ from water via electrolysis, or creating $\mathrm{CO}$ (or a more suitable electron carrier) from reduction of $\mathrm{CO}_{2}$, and using that carrier to support fermentation. Such alternatives may be more practical strategies for achieving high electron transfer rates and density. Hybrids of the generations mentioned in Table 1 are also feasible, and challenging, for example using electrophilic microorganisms taking electrons directly from photovoltaic cells [1]. In the end, flexible manufacturing concepts, using a portfolio of different renewable feedstocks and renewable energies, could well be the winning solution to bring a large suite of additional bio-products to commercialization.

Replacing fossil-based chemicals by bio-based counterparts is attractive in many cases [3] but leads to biological and processing challenges that are treated in later sections. Many novel chemicals can be produced as well [6]. Sometimes a desired metabolic pathway is available [7], but in other cases novel enzymes are required [8]. The lengthy and expensive efforts to develop bio-based chemicals should be justified by the expected revenues in combination with high innovation prominence to prevent putative competitors to enter the field. In case of commodities, lab processes with close to theoretically optimum yields need to be transferred successfully to large volumes for industrial scale production. In case of high value fine chemicals, often very complex intracellular conversions need to be debottlenecked to access products of outstanding functionality that can meet severe quality constraints. Once the cost of the development efforts and manufacturing can be reduced, the number of commercially justifiable targets will become much larger, and thus the bio-based approach will have much greater positive impact on the planet. While most of the efforts entail and most of this article describes de novo creation of carbon-based products from virgin carbon sources, novel waste recycling and inorganic applications are worth mentioning briefly as well.

To minimize plastics accumulation in nature, there is currently much interest in biodegradable polymers [9]. An even more sustainable approach is the re-use and recycling of plastics, but this leads to quality degradation and poor competitiveness with de novo synthesized material, and thus the vast majority of plastic waste is incinerated, landfilled, or released into the environment [10]. Chemical recycling, which entails (partial) depolymerization, purification, and repolymerization, is gaining traction [11], but also suffers from low added value. The identification of plastic-degrading 
microorganisms [12] and enzymes [13] now provides an opportunity for the biotechnological conversion of (mixed) plastic waste into value-added products [14, 15]. In combination with microbial and enzymatic processes for the renewable production of suitable plastic monomers, this would enable the closing of multi-million tonne carbon cycles.

Several inorganic products are also worth mentioning. Silicates with useful properties as nanostructured materials may be obtained from diatoms [16]. Industrial production and application of these materials is challenging, however. Genome editing of diatoms [17], might lead to tailoring the silicate structures in the future. Nanoparticles of metals and metal oxides, such as silver [18] and magnetite [19] can also be produced using microbial approaches.

\section{Challenges in bioprocess engineering}

\section{Begin with the end in mind}

Bioprocess engineering is the key competence to bring biotech innovations to the factories, to take markets positions and capture opportunities for societal benefits. An important success factor will be an attitude of all involved researchers to 'begin with the end in mind'. Innovative, efficient largescale bioprocess designs should be conceived, taking into account three factors [20]:

1. The whole bioprocess value chain: the product specifications and downstream purification schemes should be set before defining the upstream sections. Noteworthy, biotechnologically produced drop-in chemicals may come along with by-product impurities that are new to existing chemical routes and infrastructure [21].

2. The time perspective: start in the future, assuming what feedstock and product-market combinations will be in place and then work backward to today, including price targets and estimated annual market volumes.

3. The scale of operation: the industrial operation sets the boundaries for all lab-scale research and development, and not vice versa. In this way, an ideal process is defined taking constraints from anticipated manufacturing into account. The consequence is that a microorganism should be selected or constructed that best fits the process, and not that the process should be designed based on existing organism properties.

To arrive at solutions that are environmentally, socially and economically advantaged, a full sustainability analysis should be performed, ex-ante, during the design approach [22].

\section{Ambitions are increasing}

When considering such an ideal bioprocess, aspirations (not all achievable to the same degree in parallel) should be:

- Zero carbon spills: develop resource-conversion-product combinations that minimize $\mathrm{CO}_{2}$ and other byproduct formation. Examples include cell retention (also by using biofilms) to minimize cell growth, full product recovery, valorization of any byproduct, and metabolic engineering to optimize biosynthetic pathways.

- Zero energy spills: develop approaches that eliminate the need for energy-intensive aseptic methods and product recovery methods; consider extremophiles [23] or xenobiotic nutrients [24] for nonsterile fermentation, and aim at water-insoluble products (gaseous, oily, or solid).

- Zero water spills: minimize introduction of water with the feed streams, using hosts that tolerate high substrate and product concentrations. Apply water recycle solutions.

- Zero pH swings: minimize need for introducing pH-controlling agents; consider acidophilic/alkaliphilic production hosts for production of acids/bases.

- Zero $\mathrm{O}_{2}$ fermentation: use anaerobic conversions, for the highest efficiency from feedstock to product [3]. 
- Zero $\mathrm{N}_{2}$ fermentation: if $\mathrm{O}_{2}$ is unavoidable, consider using pure $\mathrm{O}_{2}$ rather than air [25] to enable intensification, while keeping dissolved $\mathrm{O}_{2}$ at nontoxic concentrations.

- Zero process variability: minimize variability in processes across the duration of a fermentation and between fermentations, to simplify manufacturing operations; optimal process conditions are maintained over a long production period using robust, continuous processes at steady state.

- Zero development time: minimize R\&D costs; the process should be developed quickly, at low costs, and scaled-up without losses or failures.

Industry does not yet meet these bioprocess ambitions (Box 3). The challenges for biological engineering directly follow from these ambitions (see next section). In addition, these ambitions inspire development of highly improved process development tools, incorporating known process systems engineering tools [26, 27] including better and standardized open-source process simulation tools and databases. Optimized industrial bioreactors should be designed to operate near the techno-economical limits of mass and energy transfer [20]. Computational fluid dynamics (CFD) should be integrated with cellular kinetic models (computational reaction dynamics, CRD) and agent-based modelling, for improving the design of scale-down simulators and microorganisms [28].

\section{Challenges in biological engineering}

In order to achieve the goals set for bioprocess engineering, advanced tools for strain engineering and optimization will be required. These will include genetic engineering objectives like integration of genes encoding high-activity and high-specificity enzymes needed for product biosynthesis, reprogramming of central carbon metabolism reactions [29], and also modulation of cellular flux partitioning and regulation in response to extracellular conditions. These modifications are summarized using the terms biological engineering and metabolic engineering, i.e. the best possible design of a production organism. We might coin such organisms fermenterphiles. Recent technical and scientific advances provide opportunities for exciting novel research and development to improve biological engineering:

- Automated strain construction using novel genome editing tools (e.g., CRISPR/Cas [30]), leading to revolutionary acceleration of genetic engineering and rapid strain development $[31,32]$.

- Improved strain robustness, both towards rapid fluctuations in the environment of large bioreactors and towards high concentrations of (toxic) products. Diverse host systems and extended genetic resources (e.g., environmental screening [33, 34] and new culture technologies [35]) will accelerate such developments.

- Improved model based predictions from increased understanding of microbial cells and consortia thereof [36]. This includes the application of generic correlation models (like artificial intelligence algorithms and machine learning) that can lead to fast workflows to predict improved strains.

- Rapidly increasing ease and speed of identifying new genes that encode new enzymes that catalyze desired or interesting reactions. This includes whole genome sequencing, annotation, documentation, and gene (function) discovery [37, 38].

CRISPR/Cas was developed about a decade ago and is currently the simplest and most versatile method for chromosomal genetic modifications [39] provided that cells possess necessary recombineering properties to repair DNA breaks in the desired manner. This technique is now available for routine application in a wide variety of organisms, enabling the rapid development of engineered organisms. Together with systems biotechnology for strain analysis [40], predictive modelling and bioprocess technology for the (downstream) process design, this will allow for rapid and more precise development of ideal, sustainable production systems fine-tuned for high 
performance in large-scale bioreactors. These interdisciplinary technologies promise to drastically reduce the development time as well as reduce the required development resources. The genetic engineering tools, in conjunction with ultra-high-throughput screening [41] and computational assistance by the growing possibilities in artificial intelligence and machine learning [42], will further accelerate and standardize integrated strain and bioprocess development.

Using microbial monocultures is state-of-the-art in industrial production processes. Applications of mixed cultures are rather restricted to fields such as food production, wastewater treatment and biogas formation. However, in their native habitats most microorganisms are typically growing in consortia. As such they react to external stress conditions via concerted interactions, thereby producing highly attractive compounds of commercial interest such as nutraceuticals and pharmaceuticals (e.g. antibiotics) $[43,44]$. Because of the current dominating focus on monocultures, the production potential of microbial consortia is by far not yet adequately exploited, or not even known $[43,45]$. However, there are a multitude of interesting compounds still waiting to be discovered and to be used for the benefit of mankind [46].

\section{Challenges in biological understanding}

The ambition of design-based biological engineering will rely on more quantitative analysis, modeling and understanding of biological networks. Current approaches, using genomics and synthetic biology tools, are applied to redesign model organisms [47, 48]. Most successful were approaches that include laboratory evolution or exploitation of natural diversity and reverse engineering of relevant characteristics, based on genome sequences and genome-wide expression analysis [49]. Nevertheless, current approaches are far from design-based, i.e. several rounds of designs or evolution are needed to obtain a required function. In other engineering fields, like microchip fabrication, design is fully computer based (in silico models) [50]. One reason for the lack of model-based design is the limited knowledge of biological network regulation [51].

Natural environments of microorganisms have exerted evolutionary pressure towards optimization of their metabolism and its regulation toward reproduction/proliferation. For artificial environments like industrial bioreactors, mechanistic knowledge about such processes is limited, hampering (re)engineering of metabolic and genetic regulation towards robust production hosts [52]. It has been shown that typical bioreactor conditions not only induce frequent metabolic and transcriptional changes, but also increase maintenance energy demands $[53,54]$. The regulatory program of the stringent response, natively used to strategically adapt cells to environmental changes, was shown to be switched on/off frequently and unnecessarily. Engineered cells with interrupted stringent response signaling are disconnected from environmental changes [55] thus representing a first example of particular strain design for large-scale applications. Furthermore, the example illustrates that short-term stimuli, imposed in poorly mixed bioreactor zones also impact well-mixed zones via the initiation of signaling pathways. Consequently, comprehensive simulations of large-scale microbial performance necessarily should consider not only the metabolic but also the transcriptional and post-transcriptional (regulatory) level to fully predict cellular behavior [56].

The complexity of cellular systems originates from large spatial and temporal scales as well as from yet uncharacterized interactions like allosteric and post-transcriptional regulation. A very fast metabolism, turnover in proteins as well as population heterogeneity [57] are further challenges in the modeling of cellular properties. The next key step to be taken is a model-based integration across the scales of metabolites, cells, and their environment - from the environment, to metabolic signals and genetic regulation, to unravel the regulation of growth, metabolism and gene expression [58]. With such models (thus quantitative understanding) at hand, design of optimal microbial cell factories can be performed in silico, comparable to current design processes in electronics, without 
long cycles and high throughput of building and testing. Developing these models is highly challenging, and requires novel approaches in computation and more accurate and extensive experimental measurements. While the past decade of -omics technology delivered massive amounts of data, these are not always sufficient for quantitative and predictive approaches. Systems Biotechnology has to close this gap. Grand challenges in Systems Biotechnology include:

- Extension of fundamental knowledge for in vivo gene and protein functions to obtain more realistic genome-scale models.

- Eukaryotic metabolism (from yeast to human): Compartmentation of metabolism and regulation, interaction between cell-cycle and metabolism, transcriptional and posttranscriptional regulation of enzyme activities, feedback and feedforward loops.

- Interactions between different species in microbial eco-systems, i.e. unraveling food chains and signaling interactions (e.g., for applications in wastewater treatment, gut, human diseases, biofilms).

- Integration of cell-models with the (large-scale) bioreactor environment.

- Understanding of the population behavior based on single cell variation and heterogeneity (genetic as well as non-genetic), including the prediction of evolutionary trajectories in cultivation systems.

- Definition of the stable and robust minimum of cellular metabolic flux and control networks.

\section{Concluding remarks}

The ambition to create a fully sustainable and widely applicable industrial biotechnology depends on advances in several fields: Bioprocess engineering, biological engineering as well as fundamental biological understanding (see Figure 1 and Outstanding Questions box). Furthermore, the different fields have to be well connected and integrated, for example by using rigorous mathematical modeling at all levels. Progress in modeling is observed for different levels: (1) hydrodynamics and mixing of large scale-bioreactor in combination with (currently simple) cellular models [57], (2) stoichiometric and kinetic models of metabolism partly including transcription and translation [59], (3) whole cell modeling approaches combining metabolism, signaling and biomass synthesis [58]. An integration of these modeling advancements results in a multi-scale model that cannot be computed yet. Nevertheless, such an integration of large-scale bioreactor models (CFD) with cellular models (CRD) could be in the center of future approaches to enable a predictive, cell, environment, and process based scale-up. Filling the details of cellular models requires systems biotechnology to develop mechanistic or other types of models based on intracellular measurements under dynamic scale-down conditions, allowing for predictive simulations. Analyzing these integrated models gives insights and allows predictions of fruitful avenues of engineering of the microbial host towards the ideal process performance ambitions such as zero spills, zero failures and minimal development time.

Next to the mathematical engineering and design tools, lab-technologies support the development: Automated strain construction, screening and validation. Especially, automated strain construction has been boosted by advances in genetic engineering approaches [60] as well as reliable DNA synthesis [61] together with improved liquid handling robots [62]. Artificial intelligence (or machine learning) can assist in the process of big data analysis and interpretation [63]. 


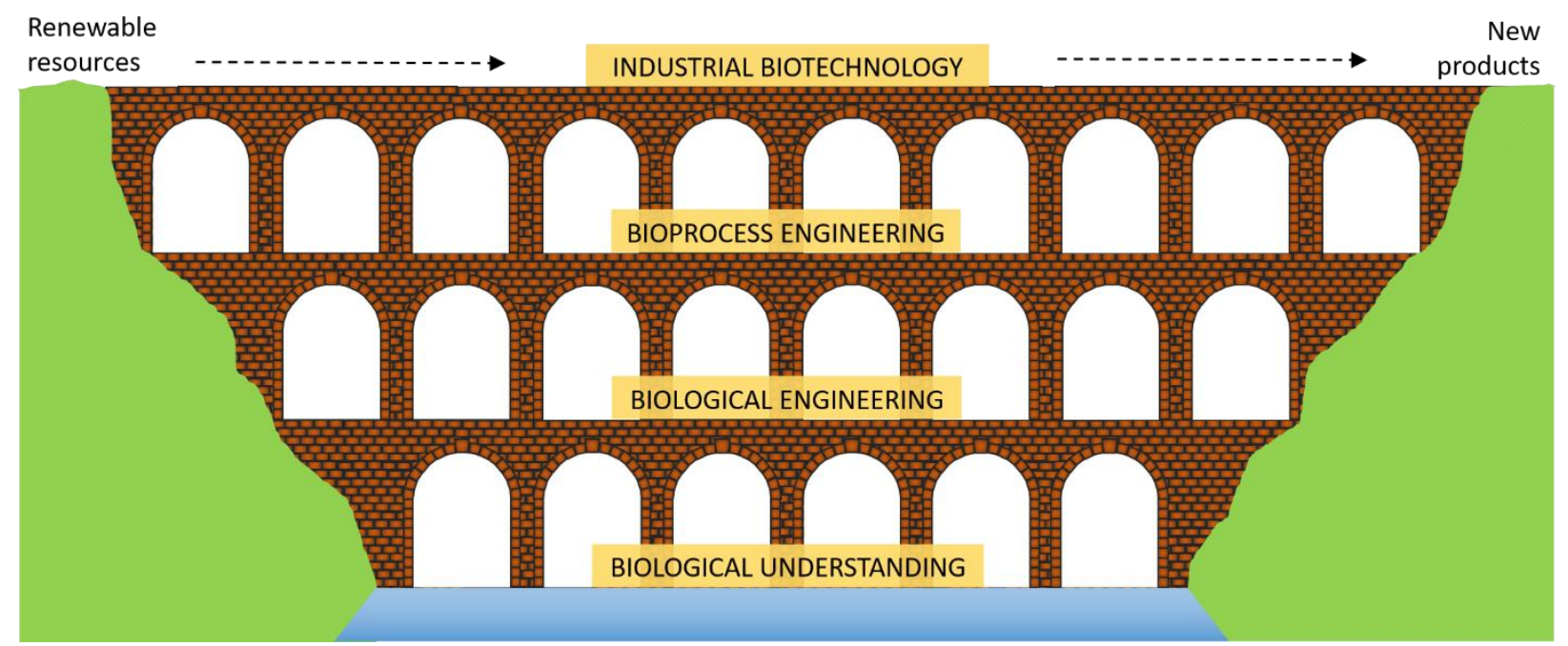

Figure 1. Transformation of available substrates (renewable resources) into desired products by industrial biotechnology requires three applied levels that build upon fundamental knowledge. This is shown symbolically by a three-level bridge. Its strength and capacity are governed by the quality of individual bricks as well as their quantity and positioning.

\section{Outstanding Questions Box}

- How to establish rigorous and predictive mathematical descriptions of biological systems?

- How to use such descriptions for designing industrial production systems (i.e., integrated strain and bioprocess)?

- How to prioritize the natural resources and the bioproducts for which the bio-based production systems should be designed?

- How to perform and optimize the engineering to obtain the desired host organisms and production processes, with minimum required investment?

\section{Acknowledgements}

Many others contributed to discussing the topic, including Mark Bisschops, Xavier Casadevall, Sergi Astals-Garcia, Cees Haringa, Michael Fink, Robbert Kleerebezem, Sarah Lieder, Mark van Loosdrecht, Filip Meysman, Peter Mooij, Patricia Osseweijer, Elena Torfs, Charilaos Xiros, Marcel Wubbolts, and Edwin Zondervan.

\section{References}

1. Woo, H.M. (2017) Solar-to-chemical and solar-to-fuel production from $\mathrm{CO}_{2}$ by metabolically engineered microorganisms. Curr Opin Biotechnol 45, 1-7.

2. Moscoviz, R. et al. (2016) Electro-fermentation: How to drive fermentation using electrochemical systems. Trends Biotechnol 34, 856-865.

3. Straathof, A.J.J. and Bampouli, A. (2017) Potential of commodity chemicals to become bio-based according to maximum yields and petrochemical prices. Biofuels Bioprod Bioref 11, 798-810. 
4. Schmitz, S. et al. (2015) Engineering mediator-based electroactivity in the obligate aerobic bacterium Pseudomonas putida KT2440. Front Microbiol 6, 284.

5. Li, C. et al. (2017) Stay connected: Electrical conductivity of microbial aggregates. Biotechnol Adv 35, 669-680.

6. King, J.R. et al. (2016) Accessing Nature's diversity through metabolic engineering and synthetic biology. F1000Research 5, F1000 Faculty Rev-397.

7. Straathof, A.J.J. (2014) Transformation of biomass into commodity chemicals using enzymes or cells. Chem Rev 114, 1871-1908.

8. Mak, W.S. et al. (2015) Integrative genomic mining for enzyme function to enable engineering of a nonnatural biosynthetic pathway. Nat Commun 6, 10005.

9. Narancic, T. et al. (2018) Biodegradable plastic blends create new possibilities for end-of-life management of plastics but they are not a panacea for plastic pollution. Environ Sci Technol 52, 1044110452.

10. Geyer, R. et al. (2017) Production, use, and fate of all plastics ever made. Science Adv 3, e1700782.

11. Garcia, J.M. and Robertson, M.L. (2017) The future of plastics recycling. Science 358, 870-872.

12. Yoshida, S. et al. (2016) A bacterium that degrades and assimilates poly(ethylene terephthalate). Science 351, 1196-1199.

13. Wei, R. and Zimmermann, W. (2017) Microbial enzymes for the recycling of recalcitrant petroleumbased plastics: how far are we? Microb Biotechnol 10, 1308-1322.

14. Wierckx, N. et al. (2015) Plastic waste as a novel substrate for industrial biotechnology. Microb Biotechnol 8, 900-3.

15. Wierckx, N. et al. (2018) Plastic biodegradation: Challenges and opportunities. In Consequences of Microbial Interactions with Hydrocarbons, Oils, and Lipids: Biodegradation and Bioremediation (Steffan, R. ed), pp. 1-29, Springer International Publishing.

16. Wang, Y. et al. (2013) Preparation of biosilica structures from frustules of diatoms and their applications: current state and perspectives. Appl Microbiol Biotechnol 97, 453-60.

17. Daboussi, F. et al. (2014) Genome engineering empowers the diatom Phaeodactylum tricornutum for biotechnology. Nat Commun 5, 3831.

18. Viorica, R.P. et al. (2017) Lactococcus lactis as a safe and inexpensive source of bioactive silver composites. Appl Microbiol Biotechnol 101, 7141-7153.

19. Sadhukhan, J. et al. (2017) Life cycle assessment of sustainable raw material acquisition for functional magnetite bionanoparticle production. J Environ Manage 199, 116-125.

20. Noorman, H.J. and Heijnen, J.J. (2017) Biochemical engineering's grand adventure. Chem Eng Sci 170, 677-693.

21. Takors, R. et al. (2018) Using gas mixtures of $\mathrm{CO}, \mathrm{CO} 2$ and $\mathrm{H} 2$ as microbial substrates: the do's and don'ts of successful technology transfer from laboratory to production scale. Microb Biotechnol 11, 606625.

22. You, F.Q. et al. (2012) Optimal design of sustainable cellulosic biofuel supply chains: Multiobjective optimization coupled with life cycle assessment and input-output analysis. AlChE J 58, 1157-1180.

23. Chen, Z. and Wan, C. (2017) Non-sterile fermentations for the economical biochemical conversion of renewable feedstocks. Biotechnol Lett 39, 1765-1777.

24. Shaw, A.J. et al. (2016) Metabolic engineering of microbial competitive advantage for industrial fermentation processes. Science 353, 583-586.

25. Chang, H.N. et al. (2010) Economic evaluation of off-gas recycle pressure swing adsorption (PSA) in industrial scale poly(3-hydroxybutyrate) fermentation. Biotechnol Bioproc Eng 15, 905-910.

26. Kokossis, A. and Yang, A. (2010) On the use of systems technologies and a systematic approach for the synthesis and the design of future biorefineries. Comput Chem Eng 34, 1397 - 1405.

27. Hemmerich, J. et al. (2017) Generic protocol for optimization of heterologous protein production using automated microbioreactor technology. $J$ Vis Exp, e56234. 
28. Delvigne, F. et al. (2017) Bioprocess scale-up/down as integrative enabling technology: from fluid mechanics to systems biology and beyond. Microb Biotechnol 10, 1267-1274.

29. Meadows, A.L. et al. (2016) Rewriting yeast central carbon metabolism for industrial isoprenoid production. Nature 537, 694.

30. Wright, Addison V. et al. (2016) Biology and applications of CRISPR systems: harnessing Nature's toolbox for genome engineering. Cell 164, 29-44.

31. Horwitz, Andrew A. et al. (2015) Efficient multiplexed integration of synergistic alleles and metabolic pathways in yeasts via CRISPR-Cas. Cell Systems 1, 88-96.

32. Chandran, S. and Shapland, E. (2017) Efficient assembly of DNA using yeast homologous recombination (YHR). In Synthetic DNA: Methods and Protocols (Hughes, R.A. ed), pp. 187-192, Springer New York.

33. Willrodt, C. et al. (2015) Guiding efficient microbial synthesis of non-natural chemicals by physicochemical properties of reactants. Curr Opin Biotechnol 35, 52-62.

34. Volmer, J. et al. (2015) Guiding bioprocess design by microbial ecology. Curr Opin Microbiol 25, 25-32.

35. Limberg, M.H. et al. (2017) Metabolic profile of 1,5-diaminopentane producing Corynebacterium glutamicum under scale-down conditions: Blueprint for robustness to bioreactor inhomogeneities. Biotechnol Bioeng 114, 560-575.

36. Kuhn, D. et al. (2010) Systems biotechnology - Rational whole-cell biocatalyst and bioprocess design. Eng Life Sci 10, 384-397.

37. Crits-Christoph, A. et al. (2018) Novel soil bacteria possess diverse genes for secondary metabolite biosynthesis. Nature 558, 440-444.

38. Owen, C. et al. (2017) Harnessing plant metabolic diversity. Curr Opin Chem Biol 40, 24-30.

39. Donohoue, P.D. et al. (2018) Advances in industrial biotechnology using CRISPR-Cas systems. Trends Biotechnol 36, 134-146.

40. Marcellin, E. and Nielsen, L.K. (2018) Advances in analytical tools for high throughput strain engineering. Curr Opin Biotechnol 54, 33-40.

41. Cole, R.H. et al. (2017) Printed droplet microfluidics for on demand dispensing of picoliter droplets and cells. Proc Natl Acad Sci U S A 114, 8728-8733.

42. Bohannon, J., A new breed of scientist, with brains of silicon, Science, 2017, July 5th.

43. Hoelzle, R.D. et al. (2014) Regulation mechanisms in mixed and pure culture microbial fermentation. Biotechnol Bioeng 111, 2139-2154.

44. Stierle, A.A. et al. (2017) The berkeleylactones, antibiotic macrolides from fungal coculture. J Nat Prod 80, 1150-1160.

45. Noack, S. and Baumgart, M. (2019) Communities of niche-optimized strains: Small-genome organism consortia in bioproduction. Trends Biotechnol 37, 126-139.

46. Schmidt-Dannert, C. (2017) The future of biologically inspired next-generation factories for chemicals. Microb Biotechnol 10, 1164-1166.

47. Nielsen, J. et al. (2013) Metabolic engineering of yeast for production of fuels and chemicals. Curr Opin Biotechnol 24, 398-404.

48. Peralta-Yahya, P.P. et al. (2012) Microbial engineering for the production of advanced biofuels. Nature 488, 320-328.

49. Oud, B. et al. (2013) Genome duplication and mutations in ACE2 cause multicellular, fast-sedimenting phenotypes in evolved Saccharomyces cerevisiae. Proc Natl Acad Sci USA 110, E4223-31.

50. Way, J. et al. (2014) Integrating biological redesign: Where synthetic biology came from and where it needs to go. Cell 157, 151-161.

51. Piazza, I. et al. (2018) A map of protein-metabolite interactions reveals principles of chemical communication. Cell 172, 358-372.e23.

52. Rugbjerg, P. et al. (2018) Diverse genetic error modes constrain large-scale bio-based production. Nature Commun 9, 787. 
53. Loffler, M. et al. (2016) Engineering E. coli for large-scale production - Strategies considering ATP expenses and transcriptional responses. Metab Eng 38, 73-85.

54. van den Brink, J. et al. (2009) Energetic limits to metabolic flexibility: responses of Saccharomyces cerevisiae to glucose-galactose transitions. Microbiology 155, 1340-1350.

55. Michalowski, A. et al. (2017) Escherichia coli HGT: Engineered for high glucose throughput even under slowly growing or resting conditions. Metab Eng 40, 93-103.

56. Nieß, A. et al. (2017) Repetitive short-term stimuli imposed in poor mixing zones induce long-term adaptation of E. coli cultures in large-scale bioreactors: experimental evidence and mathematical model. Front Microbiol 8, 1195.

57. Haringa, C. et al. (2018) Computational fluid dynamics simulation of an industrial P. chrysogenum fermentation with a coupled 9-pool metabolic model: Towards rational scale-down and design optimization. Chem Eng Sci 175, 12-24.

58. Karr, J.R. et al. (2012) A whole-cell computational model predicts phenotype from genotype. Cell 150, 389-401.

59. Kotte, O. et al. (2010) Bacterial adaptation through distributed sensing of metabolic fluxes. Mol Syst Biol 6, 355.

60. de Kok, S. et al. (2014) Rapid and reliable DNA assembly via ligase cycling reaction. ACS Synth Biol 3, 97-106.

61. Kosuri, S. and Church, G.M. (2014) Large-scale de novo DNA synthesis: technologies and applications. Nature Meth 11, 499.

62. Sackmann, E.K. et al. (2016) Technologies that enable accurate and precise nano- to milliliter-scale liquid dispensing of aqueous reagents using acoustic droplet ejection. $J$ Lab Autom 21, 166-177.

63. Kaufmann-Malaga, B. et al., Automating bioengineering: First the hands, then the head, in: KeshavarzMoore, E. and Buckland, B. (Eds.) Microbial Engineering, ECI Symposium Series, 2018.

64. Cueto-Rojas, H.F. et al. (2015) Thermodynamics-based design of microbial cell factories for anaerobic product formation. Trends Biotechnol 33, 534-546.

65. Milton, R.D. et al. (2017) Bioelectrochemical Haber-Bosch process: An ammonia-producing $\mathrm{H}_{2} / \mathrm{N}_{2}$ fuel cell. Angew Chem Int Ed 56, 2680-2683.

66. Jansen, M.L.A. and van Gulik, W.M. (2014) Towards large scale fermentative production of succinic acid. Curr Opin Biotechnol 30, 190-197.

67. Lynd, L.R. et al. (2017) Cellulosic ethanol: status and innovation. Curr Opin Biotechnol 45, 202-211.

68. Liew, F. et al. (2016) Gas fermentation - a flexible platform for commercial scale production of lowcarbon-fuels and chemicals from waste and renewable feedstocks. Front Microbiol 7, 694.

69. Heijstra, B.D. et al. (2017) Gas fermentation: cellular engineering possibilities and scale up. Microb Cell Fact 16, 60.

70. Brennan, L. and Owende, P. (2010) Biofuels from microalgae - A review of technologies for production, processing, and extractions of biofuels and co-products. Renew Sust Energ Rev 14, 557-577.

\section{Glossary}

Biological Engineering: Systematic approaches to obtain the best possible organism(s) for a desired performance.

CRISPR-Cas: Method for removing and adding genes at a desired location in a cell's genome.

Computational fluid dynamics: Numerically simulating systems involving fluid flow.

Electro-fermentation: Fermentation process in which polarized electrodes are employed by microorganisms as either electron sinks or sources.

Fourth generation processes: Electricity-driven biotechnological processes. 
Industrial biotechnology: Biotechnology applied to industrial processes.

Metabolic engineering: The practice of optimizing genetic and regulatory processes within cells to increase the cells' production of a certain substance.

Systems Biotechnology: Systems Biology approaches applied to industrial biotechnology, i.e. the quantitative analysis and design of microorganisms using for example quantitative physiology, metabolic flux analysis, and model based data evaluation. 


\section{Box 1: Why microbes for conversions of biomass to fuels and chemicals?}

- Sustainability demands the use of the most efficient combination of renewable resources of carbon and energy.

- Microbial conversions often occur under ambient conditions with respect to temperature, pressure and $\mathrm{pH}$, so relatively low energy input is required compared to conventional chemical reactions. Theoretical performance limits are dictated by stoichiometry and thermodynamics using renewable resources that pave the way to a circular economy [64].

- Microbes already make a very wide diversity of organic molecules with many beneficial properties, which can be used as drop-in replacements or improved materials.

- Microbes have been and will continue to be reprogrammed to make an even wider diversity of products, at high regio- and enantioselectivity. This avoids tedious protective group chemistry in the conventional routes, such that less conversion operations are needed between renewable resource and product [7].

Thus, multiple consecutive chemical conversion operations can often be replaced by a single, selective conversion step using engineered microorganisms.

\section{Box 2: Nitrogen-containing organic products}

Organic products containing $\mathrm{N}$-atoms are currently produced using fossil-intensive $\mathrm{NH}_{3}$, manufactured via the Haber-Bosch process which comprises over $1 \%$ of the world's energy consumption [65]. About $10 \%$ of the $\mathrm{NH}_{3}$ is directly converted into organic chemical products, by petrochemical processes as well as by $1^{\text {st }}$ generation fermentation processes. The latter use transforms renewable carbon (carbohydrate), but still relies heavily on fossil energy via $\mathrm{NH}_{3}$, used as fertilizer for growing crops (accounting for about $90 \%$ of the global $\mathrm{NH}_{3}$ outlet). However, using microorganisms that have been engineered for improved $\mathrm{N}$-fixation from $\mathrm{N}_{2}$ and harboring an appropriate product pathway, electro-fermentation might provide the necessary metabolic energy for renewable production of $\mathrm{N}$-compounds without involving $\mathrm{NH}_{3}$.

\section{Box 3. How close is industry to "zero-concepts"?}

The Biosuccinium fermentation technology for succinic acid production can serve as leading example [66]. It uses acidophilic conditions, way below the $\mathrm{p} K_{\mathrm{a}}$ of the acid, which minimizes addition of titrants during fermentation and product recovery, resulting in close-to-zero associated waste salt production. However, due to the high proton shuttling across the cell membrane, the fermentation still requires oxygen as electron acceptor to generate enough ATP via glucose dissimilation to $\mathrm{CO}_{2}$. Hence, zero-oxygen conditions are not yet feasible. However, metabolic engineering has minimized the formation of organic by-products and associated carbon spills, and cell retention further allows near-zero cell growth conditions, with virtually no bleeds of spent biomass. $\mathrm{O}_{2}$ enriched air can be used, which increases the $\mathrm{CO}_{2}$ concentration in the process such that no additional $\mathrm{CO}_{2}$ supply is needed. Despite $\mathrm{pH}$ values around 3 , and the use of minimal media, still aseptic conditions are required to reduce contamination. Further, the total energy consumption remains significant due to downstream water removal, despite the relatively high succinic acid titers $(>120 \mathrm{~g} / \mathrm{L})$. Summarizing, scale-up from 0.01 to $>100 \mathrm{~m}^{3}$ was successful, and a significant stride was made on the zero-factors, but still more advances are needed to achieve the zero-ideal. For other high-performance fermentation processes [7], such as 1,3propanediol (still not anaerobic), farnesene (still downstream processing needed to separate the product from the broth) and gluconic acid (still significant water needs to be evaporated despite titers reported above $500 \mathrm{~g} / \mathrm{L}$ ), similar challenges remain to be solved. 